\title{
Natural killer cells associated with SARS-CoV-2 viral RNA shedding, antibody response and mortality in COVID-19 patients
}

\author{
Changqian Bao ${ }^{1 \dagger}$, Xiandong Tao ${ }^{2,3 \dagger}$, Wei Cui ${ }^{4 \dagger}$, Yuanyuan Hao ${ }^{1}$, Shuaike Zheng ${ }^{5}$, Bin $\mathrm{Yi}^{2,3}$, Tiewen Pan ${ }^{2}$, \\ Ken H. Young ${ }^{6 *}$ and Wenbin Qian ${ }^{1,7^{*}}$ (1)
}

\begin{abstract}
Coronavirus disease 2019 (COVID-19) is a novel infectious viral disease caused by the severe acute respiratory syndrome coronavirus 2 (SARS-CoV-2). Two consecutively negative SARS-CoV-2 viral RNA test (interval $\geq 24$ hours), improved respiratory symptoms and obvious absorption of inflammation in pulmonary imaging are the discharge criteria for COVID-19 patients. The clearance profile of viral RNA in the upper respiratory tract specimens, including nasopharyngeal swab and/or oropharyngeal swabs, is related to innate immune cells such as Natural Killer cells. A total of 168 patients were included for the study. In this cohort, non-severe and severe groups showed significant differences in white blood cells, neutrophils, lymphocytes, basophils and platelets counts, as well as in infection related parameters such as CRP and serum cytokine IL-6. For lymphocyte subsets tests at admission, the severe group displayed significantly lower cell counts than the non-severe group. Higher counts of total T cells, CD4 + T cells, CD8 + T cells, and NK cells in peripheral blood showed a significant correlation with the shorter time taken to obtain the first negative viral RNA test and first positive lgM/ lgG antibody test. The number of B cells was only correlated with time to achieve the first positive $\mathrm{lgM} / \mathrm{lgG}$ test. The count of NK cells was also correlated with a higher level of IgG antibody $(p=0.025)$. The lymphocytopenia group had a significantly worse survival rate $(p=0.022)$ and a longer duration $(p=0.023)$ of viral shedding than the normal lymphocyte count group. A lower NK cell count correlates the most with the worse survival rate $(p<0.001)$ and a longer duration $(p<0.001)$ of viral shedding. This study suggests the potential value of allo-Natural Killer cell therapy as an universal COVID-19 treatment strategy.
\end{abstract}

Keywords: COVID-19, SARS-CoV-2, Natural killer cell, RNA viral shedding, Antibody response

*Correspondence: ken.young@duke.edu; qianwb@zju.edu.cn ${ }^{\dagger}$ Changqian Bao, Xiandong Tao and Wei Cui contributed equally to this work

${ }^{6}$ Hematopathology Division, Department of Pathology, Duke University Medical Center, Duke University Cancer Center, Durham, NC, USA

${ }^{7}$ National Clinical Research Center for Hematologic Diseases, The First Affiliated Hospital of Soochow University, Jiangsu 215006 Suzhou, China

Full list of author information is available at the end of the article

\section{To the editor,}

A novel coronavirus, severe acute respiratory syndrome coronavirus 2 (SARS-CoV-2), has spread globally since December 2019. Factors that affect the duration of viral shedding of SARS-CoV-2 [1] have not been fully declared yet. The association between lymphocyte subsets, including Natural Killer cell count, viral RNA shedding, and antibody response remain unclear. A total of 168 COVID-19 patients were retrospectively enrolled, followed and analyzed as methods indicated (Additional file 1: Methods) for this study (Additional file 2: Table S1). Non-severe and severe groups showed

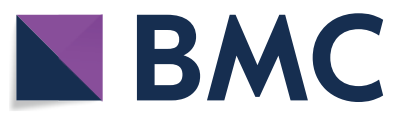

(c) The Author(s) 2021. This article is licensed under a Creative Commons Attribution 4.0 International License, which permits use, sharing, adaptation, distribution and reproduction in any medium or format, as long as you give appropriate credit to the original author(s) and the source, provide a link to the Creative Commons licence, and indicate if changes were made. The images or other third party material in this article are included in the article's Creative Commons licence, unless indicated otherwise in a credit line to the material. If material is not included in the article's Creative Commons licence and your intended use is not permitted by statutory regulation or exceeds the permitted use, you will need to obtain permission directly from the copyright holder. To view a copy of this licence, visit http://creativeco mmons.org/licenses/by/4.0/. The Creative Commons Public Domain Dedication waiver (http://creativecommons.org/publicdomain/ zero/1.0/) applies to the data made available in this article, unless otherwise stated in a credit line to the data. 
significant differences in white blood cells, neutrophils, lymphocytes, basophils and platelets counts, as well as in infection related parameters such as CRP and serum cytokine IL-6. The severe group had higher level of CRP and IL- 6 than non-severe group. For lymphocyte subsets tests at admission, the severe group displayed significantly lower cell counts than the non-severe group (Additional file 3: Table S2). SARS-CoV-2 viral RNA detection and specific IgM and IgG tests were taken at least twice per week after admission. Higher counts of total T cells, $\mathrm{CD} 4+\mathrm{T}$ cells, $\mathrm{CD} 8+\mathrm{T}$ cells, and NK cells in peripheral blood showed a significant correlation with the shorter time taken to obtain the first negative viral RNA test and first positive IgM/ IgG antibody test.The severe group required a longer time to achieve the first positive IgM/IgG test (either IgM or IgG more than $10 \mathrm{IU} / \mathrm{mL}$ )
(Additional file 4: Table S3). Inflammatory monocytes were reported to secret IL-6 and GM-CSF in COVID-19 patients,resulting in elevated IL- 6 and other cytokines such as IFN- $\gamma$ and TNF- $\alpha$ [2]. IL- 6 mediated JAK/STAT signalling which could elicit cytokines release storm (CRS) and correlated with worse prognosis. According to our data, higher CRP and IL- 6 had a significant correlation with a longer time taken to achieve the first viral RNA negative and IgM/IgG positive tests. The number of B cells was only correlated with time to achieve the first positive IgM/IgG test. The count of NK cells was also correlated with a higher level of IgG antibody $(p=0.025)$ (Additional file 5: Table S4 and Additional file 1: Additional material ). The lymphocytopenia $\left(<1 \times 10^{9} / \mathrm{L}\right)$ [3] group had a significantly worse survival rate (log-rank $p=0.022)$ and a longer duration (log-rank $p=0.023)$ of

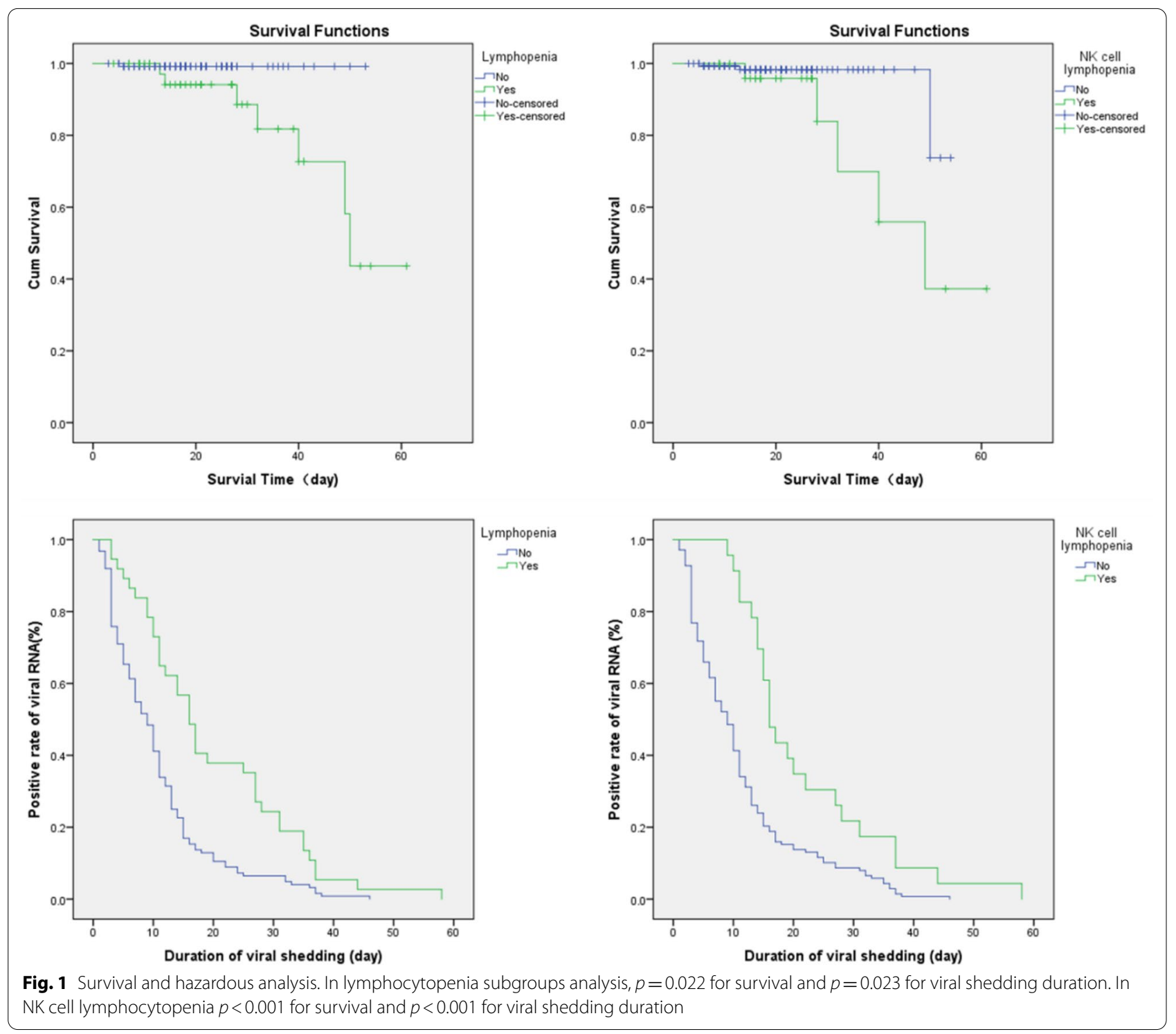


viral shedding than the normal lymphocytes count group. The NK cell lymphocytopenia $\left(<0.1 \times 10^{9} / \mathrm{L}\right)$ [4] group had a significantly worse survival rate $(\log$-rank $p<0.001)$ and a longer duration (log-rank $p<0.001)$ of viral shedding (Fig. 1).

Both innate and adaptive immune responses are essential to control viral infections. NK cells, as a part of innate immune system, play an important role during acute viral infection [5]. The strength and duration of IgG after infection is the key point of immunity from SARS-CoV-2 [6]. NK cells have a direct killing effect on virus-infected cells through the killer-cell immunoglobulin-like receptors (KIR) [7], lysis-infected cells and releasing antigen. NK cells interact with dendritic cells [8] and may play a part in processes of antigen-presentation and adaptive immunity against SARS-CoV-2. NK cell counts could be critical to the IgG immunity for COVID-19. Engagement of CD16 on NK cells by antibody-coated virus-infected cells results in antibody-dependent cellular cytotoxicity [9]. The innate immune system serves as a frontline of clearance for coronavirus and regulates immune response. We hypotheses that NK cells can directly kill virus-infected cells through degranulation, receptor mediated apoptosis, and antibody-dependent cell-mediated cytotoxicity (ADCC) (Fig. 2) [10, 11]. Also, it has been proven that NK cells conduct active crosstalk with autologous dendritic cells (DC) through a process that requires NK cell-DC cell interaction and the secretion
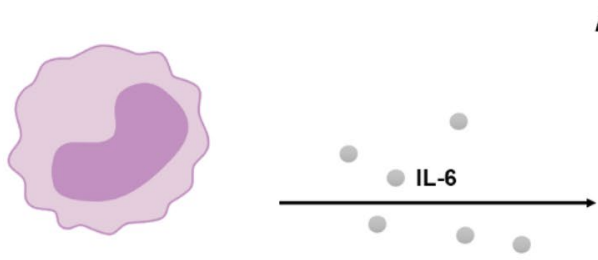

Antigen presenting and adaptive immune

Monocyte
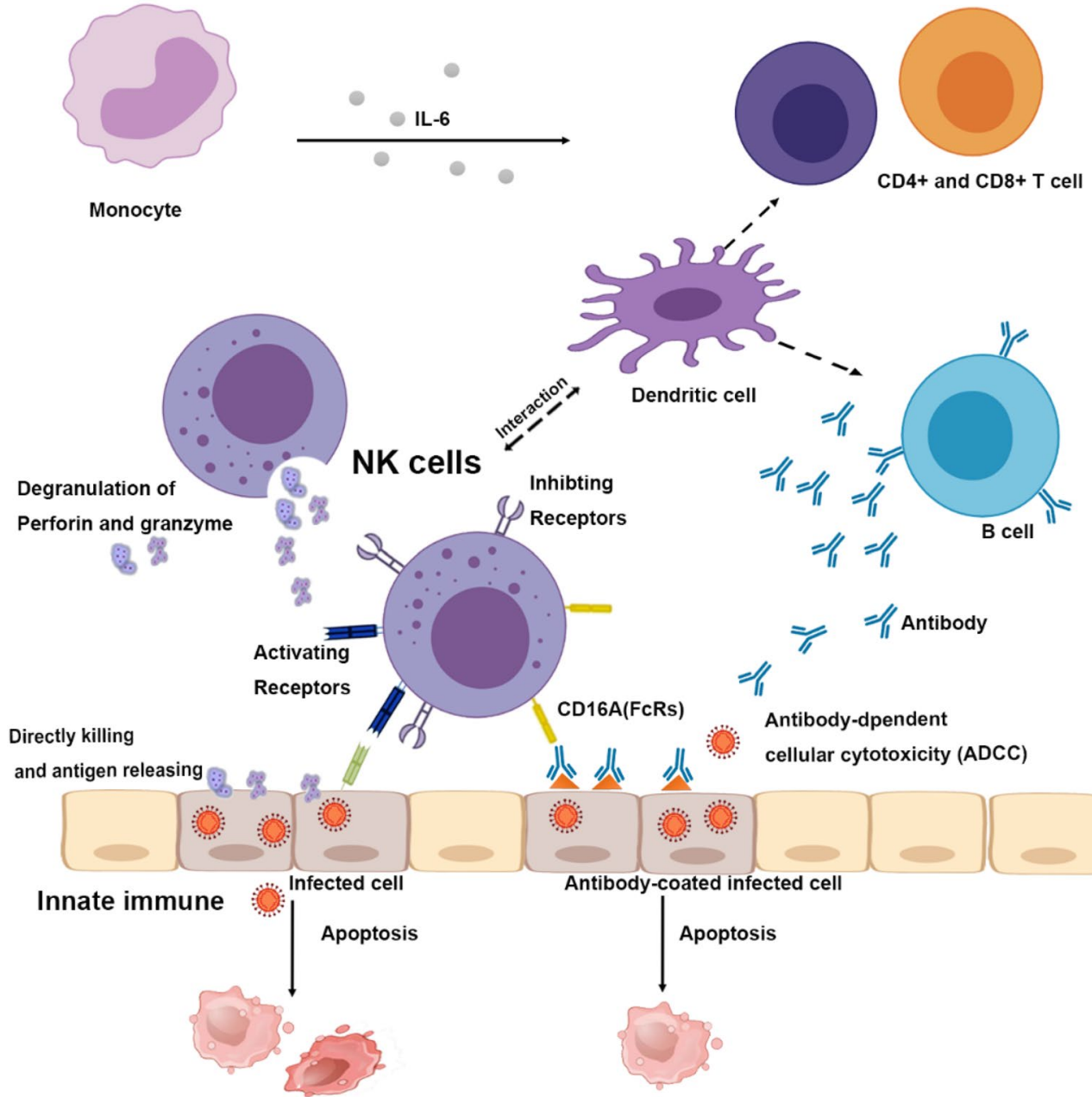

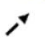

D4+ and CD8+ T cell
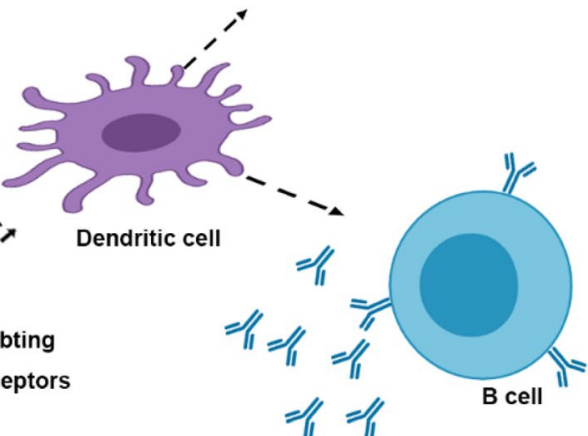

Inhibting

\& Receptors

$=\mu$

$=\%$ Antibody

$=/ 1$

Antibody-dpendent

cellular cytotoxicity (ADCC)

Fig. 2 The innate and adaptive immune response to SARS-CoV-2 infection. Hypothesis of the innate and adaptive immune response to SARS-CoV-2 infection. NK cells have direct killing effect on SARS-CoV-2 infected cells, as well as participate in antibody-dependent cellular cytotoxicity. Through inhibiting and activating receptors, NK cells recognize infected cells. Once activated, the degranulation of NK cells induces the releasing of perforin and granzyme which directly lyse infected cells. NK cells express CD16A, which participates in antibody-dependent cellular cytotoxicity. Meanwhile, NK cells also interact with dendritic cells in antigen presenting process and affect adaptive immune response. Monocytes can secret IL-6 that acts as inflammatory cytokine, resulting in the activation of other immune cells 
of specific cytokines [12]. This may explain why the NK cell count is related to a specific IgM/IgG antibody response. So far, there are four COVID-19 related NK cell clinical trials registered on Clinicaltrials.gov, including hematopoietic stem cell derived NK cells infusion (NCT04365101), NK Cells in combination with standard therapy (NCT04280224), IL-15 superagonist- and GMCSF neutralizing scFv-secreting NKG2D-ACE2 CARNK cell therapy for COVID-19 patients (NCT04324996). Natural Killer cells do not cause GVHD, which provides an off-shelf anti-viral cell therapy. This study suggests the potential of Natural Killer cells as an universal COVID19 treatment.

\section{Supplementary Information}

The online version contains supplementary material available at https://doi. org/10.1186/s40164-021-00199-1.

Additional file 1. Additional material-Methods.

Additional file 2: Table S1. Clinical characteristics of patients.

Additional file 3: Table S2. Laboratoryexamination at admission.

Additional file 4: Table S3. Time to achieve the first SARS-CoV-2 nucleic acid negative test and the first positivelgM/lgG test.

Additional file 5: Table S4. Correlation analysis.

\section{Acknowledgements}

We acknowledged all the doctors and nurses working in treatment of COVID19 patients in Huoshenshan hospital, Wuhan, China.

\section{Authors' contributions}

CB conceived the study, analyzed data, and drafted the manuscript. XT and WC collected and analyzed data. YH, SZ, BY, and TP reviewed the manuscript. $\mathrm{KY}$ and WQ supported the study technically and reviewed the manuscript. All authors read and approved the final manuscript.

\section{Funding}

This study was supported by funds from the Translation Research Grant of NCRCH (2020ZKZC01).

\section{Competing interests}

The authors declared no competing interests.

\footnotetext{
Author details

${ }^{1}$ Department of Hematology, The Second Affiliated Hospital, Zhejiang University School of Medicine, 310009 Hangzhou, China. ${ }^{2}$ The Third Affiliated Hospital of Naval Medical University, 200438 Shanghai, China. ${ }^{3}$ Wuhan Huoshenshan Hospital, 430100 Wuhan, China. ${ }^{4}$ Department of Intensive Care Unit, The Second Affiliated Hospital, Zhejiang University School of Medicine, 310009 Hangzhou, China. ${ }^{5}$ Department of Dentist, The Second Affiliated Hospital, Zhejiang University School of Medicine, 310009 Hangzhou, China.

${ }^{6}$ Hematopathology Division, Department of Pathology, Duke University
}

Medical Center, Duke University Cancer Center, Durham, NC, USA. ${ }^{7}$ National Clinical Research Center for Hematologic Diseases, The First Affiliated Hospital of Soochow University, Jiangsu 215006 Suzhou, China.

Received: 17 November 2020 Accepted: 4 January 2021

Published online: 27 January 2021

\section{References}

1. Wölfel R, Corman VM, Guggemos W, Seilmaier M, Zange S, Müller MA, Niemeyer D, Jones TC, Vollmar P, Rothe C, et al. Virological assessment of hospitalized patients with COVID-2019. Nature. 2020;581 (7809):465-9.

2. Huang C, Wang Y, Li X, Ren L, Zhao J, Hu Y, Zhang L, Fan G, Xu J, Gu X, et al. Clinical features of patients infected with 2019 novel coronavirus in Wuhan, China. Lancet. 2020;395(10223):497-506.

3. Huang I, Pranata R. Lymphopenia in severe coronavirus disease-2019 (COVID-19): systematic review and meta-analysis. J Intensive Care. 2020;8:36.

4. Ebbo M, Gérard L, Carpentier S, Vély F, Cypowyj S, Farnarier C, Vince N, Malphettes M, Fieschi C, Oksenhendler E, et al. Low circulating natural killer cell counts are associated with severe disease in patients with common variable immunodeficiency. EBioMedicine. 2016:6:222-30

5. Mazzoni A, Salvati L, Maggi L, Capone M, Vanni A, Spinicci M, Mencarini J, Caporale R, Peruzzi B, Antonelli A, et al. Impaired immune cell cytotoxicity in severe COVID-19 is IL-6 dependent. J Clin Invest. 2020;130(9):4694-703.

6. Phelan AL. COVID-19 immunity passports and vaccination certificates: scientific, equitable, and legal challenges. Lancet. 2020;395(10237):1595-8.

7. Petitdemange C, Wauquier N, Rey J, Hervier B, Leroy E, Vieillard V. Control of acute dengue virus infection by natural killer cells. Front Immunol. 2014:5:209.

8. Nakayama M, Takeda K, Kawano M, Takai T, Ishii N, Ogasawara K. Natural killer (NK)-dendritic cell interactions generate MHC class II-dressed NK cells that regulate CD4 + T cells. Proc Natl Acad Sci USA. 2011:108(45):18360-5.

9. Jegaskanda S, Vanderven HA, Tan H-X, Alcantara S, Wragg KM, Parsons MS, Chung AW, Juno JA, Kent SJ. Influenza virus infection enhances antibody-mediated NK cell functions via type\&nbsp; interferondependent pathways. J Virol. 2019;93(5):e02090-02018.

10. McKechnie JL, Blish CA. The innate immune system: fighting on the front lines or fanning the flames of COVID-19? Cell Host Microbe. 2020;27(6):863-9.

11. Grudzien M, Rapak A. Effect of natural compounds on NK cell activation. J Immunol Res. 2018;2018:4868417.

12. Ferlazzo G, Moretta L. Dendritic cell editing by natural killer cells. Crit Rev Oncog. 2014;19(1-2):67-75.

\section{Publisher's note}

Springer Nature remains neutral with regard to jurisdictional claims in published maps and institutional affiliations. 